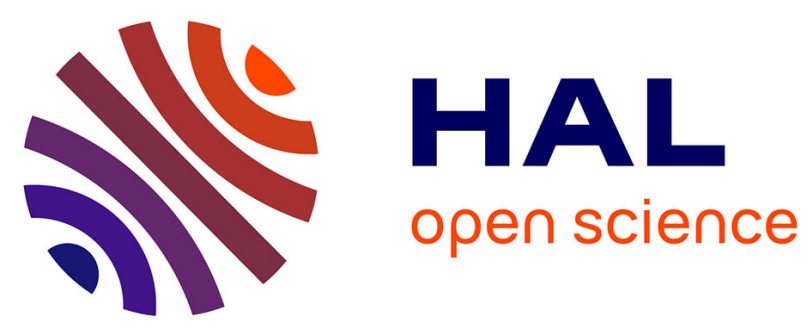

\title{
Cognitive Barriers to Readiness to Change in Alcohol-Dependent Patients.
}

Anne-Pascale Le Berre, François Vabret, Cauvin Céline, Karine Pinon, Philippe Allain, Anne Lise Pitel, Francis Eustache, Hélène Beaunieux

\section{To cite this version:}

Anne-Pascale Le Berre, François Vabret, Cauvin Céline, Karine Pinon, Philippe Allain, et al.. Cognitive Barriers to Readiness to Change in Alcohol-Dependent Patients.. Alcoholism: Clinical and Experimental Research, 2012, epub ahead of print. 10.1111/j.1530-0277.2012.01760.x . inserm-00665745

\section{HAL Id: inserm-00665745 https://www.hal.inserm.fr/inserm-00665745}

Submitted on 2 Apr 2012

HAL is a multi-disciplinary open access archive for the deposit and dissemination of scientific research documents, whether they are published or not. The documents may come from teaching and research institutions in France or abroad, or from public or private research centers.
L'archive ouverte pluridisciplinaire HAL, est destinée au dépôt et à la diffusion de documents scientifiques de niveau recherche, publiés ou non, émanant des établissements d'enseignement et de recherche français ou étrangers, des laboratoires publics ou privés. 


\section{Cognitive barriers to readiness to change in alcohol-dependent patients}

2 Anne-Pascale Le Berre ${ }^{\mathrm{a}, \mathrm{b}, \mathrm{c}, \mathrm{d}}$, François Vabret ${ }^{\mathrm{a}, \mathrm{b}, \mathrm{c}, \mathrm{e}}$, Céline Cauvin $^{\mathrm{a}, \mathrm{b}, \mathrm{c}, \mathrm{e}}$, Karine Pinon $^{\mathrm{f}}$, Philippe

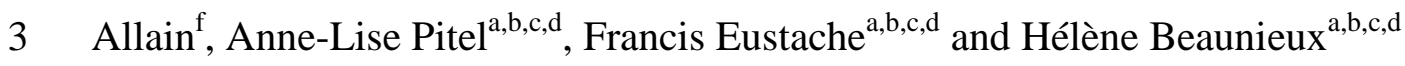

4

5 a INSERM, U1077, Caen, France

$6 \quad{ }^{\mathrm{b}}$ Université de Caen Basse-Normandie, UMR-S1077, Caen, France

$7 \quad{ }^{\mathrm{c}}$ Ecole Pratique des Hautes Etudes, UMR-S1077, Caen, France

$8 \quad{ }^{\mathrm{d}} \mathrm{CHU}$ de Caen, U1077, Caen, France

$9{ }^{\mathrm{e}} \mathrm{CHU}$ de Caen, Service d'Addictologie, Caen, France

${ }^{\mathrm{f}}$ Université d'Angers, UPRES EA 2646, Angers, France

Corresponding author: Dr Hélène Beaunieux, Unité de Recherche U1077, Laboratoire de Neuropsychologie,

13 CHU Côte de Nacre, 14033 Caen Cedex, France. Phone: +33 (0)2 310651 97; Fax: +33 (0)2 310651 98; e-

14 mail: $\underline{\text { helene.beaunieux@unicaen.fr }}$

\section{Funding}

This research was funded by Inserm and the Basse-Normandie Regional Council 18 (R07012EE).

\section{Declaration of Interest}

None of the authors has any conflicts of interest with this work, either financial or otherwise. 
Abstract

3 Background

4 Patients' personal investment and readiness to change have proved to be a prerequisite for the 5 successful treatment of alcohol addiction. The aim of this study was to determine the 6 contribution of cognitive functions to the motivation process to abandon maladjusted 7 behaviour in favour of a healthier lifestyle.

\section{Methods}

9 An adapted version of the 'readiness to change' questionnaire was completed by 31 alcohol10 dependent patients after detoxification and at alcohol treatment entry. This tool is designed to 11 assess the three main stages of motivation to change regarding alcohol consumption: precontemplation (substance abuse and no intention to stop drinking), contemplation (strong

13 intention to change habits but ambivalent behaviour) and action (cessation of excessive 14 alcohol consumption and behavioural changes for healthier habits) stages. Patients and 37 15 healthy controls also underwent an extensive neuropsychological battery including episodic memory, metamemory, executive functions and decision-making assessment.

\section{Results}

When alcohol-dependent patients were considered as a group, the mean score on the action

19 subscale was significantly higher than the precontemplation and contemplation ones.

20 Nevertheless, when the stage of change reached by each patient was considered individually, 21 we found that some alcohol-dependent patients were still in the earlier precontemplation and contemplation stages. Stepwise regression analysis revealed links between impaired memory and executive functions and low motivation, and between good decision-making skills and high motivation. 


\section{Conclusions}

2 Our results suggest that a set of complementary cognitive abilities is needed to achieve 3 awareness and resolve ambivalence towards alcohol addiction, which is essential for 4 activating the desire to change problematic behaviour.

5 Keywords: Alcohol dependence; Motivation; Episodic memory; Metamemory; Executive 6 functions; Decision-making

7

8

9

10

11

12

13

14

15

16

17

18

19

20

21

22

23

24

25

26 


\section{Introduction}

The psychological treatment of excessive alcohol consumption requires the initiation and development of intrinsic motivation to change addictive behaviour. This can be achieved through motivational interviewing, a client-centered and directive therapeutic style that helps patients to explore and resolve their ambivalence to enhance their desire to change their behaviour (Hettema et al., 2005; Miller and Rose, 2009). High motivation is the key to patients' engagement in clinical treatment (DiClemente et al., 1999). Prochaska and DiClemente's 'stages of change' (Prochaska and DiClemente, 1983; DiClemente, 2007) model comprises different stages of motivation, including 'precontemplation' (substance abuse and no intention of stopping drinking), 'contemplation' (strong intention of changing addictive habits but ambivalent attitude) and 'action' (cessation of excessive alcohol consumption and adoption of previously envisaged healthier lifestyle). To progress through the different stages and adopt permanent and sustainable healthier behavioural changes, patients must implement processes of change, which are covert and overt activities and experiences in which individuals engage in order to attempt to modify risky behaviour such as consciousness raising (increasing information about unhealthy drinking behaviour) and dramatic relief (experiencing and expressing feelings about drinking behaviour). It is well known to clinicians that alcohol-dependent patients who seek treatment can be at different levels of motivation, some of them being ready to change behaviour and others being still ambivalent and resistant to modify their unhealthy habits (e.g., Carney and Kivlahan, 1995; DiClemente and Hughes, 1990; Edens and Willoughby, 2000). This heterogeneity in motivational level at treatment entry could be explained by personal and contextual factors including demographic variables, perceived stress, perceived severity of alcohol dependence and reported drinking consequences, psychiatric comorbidity, environmental quality of life and positive treatment outcome expectancies (DiClemente et al., 2009); In addition to these 
1 previous findings, the contribution of cognitive functions to motivation to change should be

2 also investigated.

Even though efficient cognitive functioning would appear to promote abstinence, the

4 results in the literature are heterogenous. Some investigations have reported that poor 5 cognitive functioning may be predictive of difficulty in maintaining long-term abstinence 6 from alcohol (Abbott and Gregson, 1981; Allsop et al., 2000; Glenn and Parsons, 1991; 7 Gregson and Taylor, 1977; Miller, 1991; Noel et al. 2002; Parsons, 1994; Parsons et al., 1990; 8 Rourke and Grant, 1999), while others have failed to find any such link (Donovan et al., 1984; 9 Jin et al., 1998; Macciocchi et al., 1989; Moriyama et al., 2002; Pitel et al., 2009). However, cognitive impairments could indirectly influence clinical outcomes (abstinence or relapse) by affecting the influence of readiness to change, as several studies have highlighted a strong relationship between motivation to change and drinking outcome (Penberthy et al., 2007; Project MATCH Research Group, 1997, 1998). While several studies have investigated a potential association between cognitive functioning and treatment outcome (abstinence or relapse), few researchers have considered the relationships between cognitive functioning and motivation to change. Intellectual functioning, memory and executive skills have predicted greater motivation to change substance use including alcohol use among people with severe co-occurring mental disorders (Blume et al., 1999) and among college students with drinking problems (Blume et al., 2000). In addition, Severtson et al. (2010) demonstrated an association between executive functioning and motivation to enter treatment among regular users of heroin and/or cocaine. Although episodic memory (Fama et al., 2004; Pitel et al., 2007), executive functions (Sullivan et al., 2000; Moselhy et al., 2001; Pitel et al., 2007), metamemory (Le Berre et al., 2010) and decision-making (Goudriaan et al., 2005; Noel et al., 2007) are all known to be impaired in alcohol-dependent patients, only one study (Blume et al., 2005) examined the relationships between episodic memory, executive functions and the 
1 readiness to change drinking behaviour, as assessed by the 'readiness to change'

2 questionnaire (RTC, Rollnick et al., 1992), in alcohol-dependent patients who met either the

3 criteria for alcohol abuse or dependence but were not in treatment. This preliminary study

4 revealed links between motivation stages and verbal memory scores but did not show a

5 relationship with executive abilities, in accordance with another study conducted within the

6 same clinical population (Blume et al., 2009), Further studies are now required to determine

7 the specific memory components (learning, encoding, retrieval or recollection) which might

8 be associated with readiness to change in alcohol-dependent patients at treatment entry.

The aim of the present study was therefore to define the cognitive factors that might, at least partially, predict the motivational evolution to change drinking behaviour. To this end, we measured motivation with the RTC and assessed a range of neuropsychological functions, including episodic memory and executive functions and higher level cognitive functions such as metamemory and decision making.

\section{Materials and Methods}

16

\subsection{Participants}

Two groups of participants were included in this study: 31 chronic alcohol-dependent patients (mean age: $43.9 \pm 7$ years; range: $31-56$ ) and 37 controls (mean age: $45.5 \pm 6.1$ years; range: 31-60) matched for age and education. There were 25 men in the control group and 26 men in the alcohol-dependent group. Alcohol-dependent patients were early in abstinence from alcohol (mean days of sobriety before inclusion: $12.64 \pm 7.16$; range: 7-40).

Age, education level and Mini Mental State Examination (MMSE, Folstein et al., 1975), depression level and anxiety level scores are summarized in Table 1.

Performances on the MMSE were significantly poorer in the chronic alcoholdependent patients than in the controls. The depression level, measured with the self- 
1 administered Beck Depression Inventory (BDI, Beck et al., 1961), was higher in the alcohol-

2 dependent group than in the control group. Similarly, anxiety, measured with the State-Trait

3 Anxiety Inventory (STAI, Spielberger et al., 1983), was higher in the alcohol-dependent

4 group. Demographic and clinical data for patients and controls are summarized in Table 1.

\section{$5 \quad$ Insert Table 1}

Alcohol-dependent participants were recruited by clinicians on the basis of the DSM-

IV criteria for alcohol dependence (American Psychiatric Association, 1994) while they were receiving treatment for alcohol dependence as in-patients at Caen University Hospital. Patients had no history of other types of substance dependence (except tobacco), and they had already completed detoxification when they were included in the study. They were interviewed to constitute a review of their alcohol use history and typical use patterns prior to treatment including the length of alcohol-dependence and their usual daily alcohol intake over the six months prior to treatment (Table 1). None of the participants was taking psychotropic medication, displayed psychiatric problems or had any history of pathology (head injury, coma, epilepsy, Wernicke's encephalopathy, cirrhosis or depression) that might have affected their cognitive functions. Control participants were interviewed to confirm they did not drink more than 21 (men) or 14 (women) weekly standard drinks and no more than four at a time (World Health Organization criteria). Prior to inclusion, all the participants filled in a health questionnaire including questions about alcohol and drug consumption. None of the controls had a history of drug abuse. All the participants gave their informed consent to the study, 21 which was approved by the local ethics committee. 


\subsection{Materials and procedure}

\section{$2 \quad$ 2.2.1. 'Readiness to change' (RTC) questionnaire}

3 We used an adapted version of the RTC (Rollnick et al., 1992) self-report questionnaire to

4 assess motivation and readiness to change alcohol abuse behaviour. Based on the stages of 5 change model (Prochaska and DiClemente, 1983), it is made up of 12 questions divided into 6 three subscales, each corresponding to a stage of change (4 questions per subscale). These 7 three subscales correspond to the precontemplation stage ("It's a waste of time thinking about my drinking"), the contemplation stage ("I enjoy my drinking but sometimes I drink too much") and the action stage ("Anyone can talk about wanting to do something about their drinking but I am actually doing something about it"). Patients were asked to rate their agreement with statements about their alcohol consumption on a 5-point Likert-type scale ranging from 'strongly disagree' (-2) to 'strongly agree' (+2). We took the patients' scores on each subscale (ranging from -8 to 8 ) as our variables. The subscale with the highest score indicated which motivational stage the patient had reached at the time of the testing. When two or more subscale scores were equal, we considered that the scale farthest along the continuum of change (precontemplation-contemplation-action) represented the patient's stage of change. The interpretation of the motivation measures must be done as follow. A higher score on action subscale than on precontemplation and contemplation subscales refers to high level of motivation. Inversely, a higher score on precontemplation and contemplation subscales than on action subscale refers to low level of motivation

2.2.2. Neuropsychological assessments (a description of each task is provided in the online Table SM1)

Episodic memory

We assessed episodic memory with the Free and Cued Selective Reminding Test (FCSRT) (Grober and Buschke, 1987; Grober et al., 1988) for verbal learning abilities. The state of consciousness associated with memories, together with encoding and retrieval skills, 
1 was measured with the Spondee test (Pitel et al., 2007), which includes the Remember-Know

2 paradigm (Gardiner et al., 2002).

\section{Metamemory}

We assessed metamemory with the "Feeling-of-Knowing" (FOK) task (Pinon et al., 2005; Le Berre et al., 2010). After learning 20 cue-target pairs and prior to a recognition task,

6 participants were asked to say whether they thought they would recognize the target afterwards. An episodic FOK accuracy measure was then calculated (Goodman-Kruskal gamma, Nelson, 1984) to assess the agreement between predicted and actual recognition performance.

\section{Executive functions and decision-making}

We assessed executive functions with a verbal fluency task (Cardebat et al., 1990; adapted version by the Groupe de Réflexion pour l'Evaluation des Fonctions EXécutives (GREFEX), Godefroy O, 2001) for spontaneous flexibility abilities and strategic search in memory, the Trail-Making Test (Reitan, 1958; adapted GREFEX version) Part B for reactive flexibility, the Stroop test (Stroop, 1935; adapted GREFEX version) for inhibition, the Hayling test (Burgess and Shallice, 1996; French adapted version by Meulemans et al., 2001) for semantic inhibition, the Modified Card Sorting Test (MCST) (Nelson, 1976; adapted GREFEX version) for cognitive flexibility, working memory, problem-solving and setshifting abilities, and the Iowa Gambling Task (Bechara et al., 1994) for decision-making. These are well-established tests and detailed descriptions of them are widely available (Lezak 21 et al., 2004).

\subsection{Statistical analysis}

We analysed the data in four steps. First, we conducted a group analysis to describe

24 the motivational features of the alcohol-dependent group as a whole, applying a paired25 samples $t$-test to the three RTC subscale scores. In addition, we analysed individual 
1 motivation profiles to find out which stage of change each patient was, according to the RTC

2 subscale with the highest score. Second, we investigated the effects of alcohol-dependence on 3 episodic memory, metamemory, executive functions and decision-making skills, using an

4 unpaired two-sample $t$-test. Third, in order to identify the potential effect of confounding 5 factors (age, education, drinking history MMSE score and anxiety or depression levels), we 6 calculated Pearson's correlation coefficients in the alcohol-dependent group between these

7 factors and each motivation subscale score. Factors identified as being significantly correlated $(p<.05)$ with motivational data were included as covariates in a subsequent stepwise regression analysis. Fourth, a stepwise regression analysis was carried out in the alcoholdependent group to examine the best cognitive predictors of each RTC subscale score among episodic memory, metamemory, executive and decision-making scores. A probability level of .05 was adopted for all analyses.

\section{Results}

\subsection{Readiness to change}

Group analysis: The mean score on the action stage subscale was higher than the mean scores on both the precontemplation, $t(30)=-11.01, p<0.001$, and contemplation stage subscales, $t(30)=-4.18, p<0.001($ Table 2$)$.

Insert Table 2

Individual analyses: 21 alcohol-dependent patients scored highest on the action subscale, nine on the contemplation subscale and one on the precontemplation subscale.

3.2. Effects of alcohol-dependence on episodic memory, metamemory, executive functions and decision-making faculties

Results revealed that alcohol-dependent patients performed more poorly than controls on all the verbal episodic memory tasks (learning, encoding, retrieval and recollection), as 
1 well as on the metamemory measure, the executive tasks (reactive flexibility, inhibition,

2 cognitive flexibility, working memory, problem-solving and set-shifting) and the decision-

3 making measure. Data are summarized in Table 3.

$4 \quad$ Insert Table 3

\subsection{Confounding variables}

As age, education, MMSE scores, psychiatric scores and drinking variables did not correlate with the precontemplation and contemplation subscale scores in the alcoholdependent group, these variables were not included in the stepwise regression analyses for these stages. Only alcohol intake was entered as a covariate in the stepwise regression analysis conducted with the action stage score, as this drinking variable was significantly correlated with it $(r=-0.40, p=0.03)$. Detailed results of the correlations are provided in Table 4.

Insert Table 4

\subsection{Cognitive predictors of readiness to change}

Precontemplation subscale: The only cognitive predictor for the precontemplation subscale score was the level of consciousness associated with recollection (mean percentage of 'Remember' answers), which accounted for $20 \%$ of the variance. A lower state of consciousness significantly predicted higher precontemplation subscale scores $(r=-0.44, p=$ 0.01) (Fig. 1A and Table 5).

Contemplation subscale: In the first step, $23 \%$ of the variance in contemplation subscale score was account for by the time spent on the Stroop interference task. The second cognitive predictor making a significant contribution to contemplation subscale score was the number of errors for the Modified Card Sorting Test (MCST) (accounting for 15\% of the variance). Higher Stroop Color-Word time score and higher MCST number of errors scores 
1 significantly predicted higher contemplation subscale scores $([r=0.48, p=0.006]$ and $[r=$ $20.46, p=0.01]$ respectively) (Figure 1B and Table 5). Action subscale: The only cognitive predictor for the action subscale score was the decision-making measure, which accounted for $19 \%$ of the variance. Higher decision-making scores significantly predicted higher action subscale scores $(r=0.43, p=0.01)$ (Fig. 1C and

6 Table 5).

Insert Fig. 1 and Table 5

\section{Discussion}

The main objective of our study was to improve our understanding of how cognitive abilities are involved in the motivation to change addictive behaviour. More specifically, we investigated the basic and higher-level cognitive functions that are known to be impaired in alcohol-dependence to explain - at least in part - why some patients have difficulty shifting from a low level of motivation to a high level of motivation. To this end, we focused our attention on the effect of episodic memory, metamemory, executive function and decisionmaking abilities on motivation in alcohol-dependent patients early in abstinence and at clinical treatment entry.

Concerning readiness to change for the alcohol-dependent group as a whole, the mean score on the action subscale was significantly higher than the precontemplation and contemplation mean scores. This observation is not surprising, given that those patients were at alcohol treatment entry. Nevertheless, when we adopted a more qualitative approach, investigating the stage of change reached by each individual patient, we found that some patients were still in the earlier precontemplation and contemplation stages. This finding is in accordance with clinical observation that not every patient is highly motivated to change at treatment entry (e.g., Carney and Kivlahan, 1995; DiClemente and Hughes, 1990; Edens and 
1 Willoughby, 2000). Moreover, alcohol-dependent patients performed more poorly than

2 controls on the cognitive tasks, in agreement with previous studies showing episodic memory

3 impairment (Beatty et al., 1995; Fama et al., 2004; Goldstein et al., 2004; Pitel et al., 2007),

4 executive dysfunction (Fama et al., 2004; Noel et al., 2001; Pitel et al., 2007; Tedstone et

5 Coyle, 2004), metamemory decline (Le Berre et al., 2010) and decision-making deficit

6 (Goudriaan et al., 2005; Noel et al., 2007) in these patients. Our results also revealed a

7 relationship between verbal episodic memory impairment, more specifically a deficit of conscious recollection (Pitel et al., 2007), and high precontemplation scores, as well as relationships between weak executive performances and high contemplation scores, and between good decision-making skills and high action scores.

These findings suggest that patients with higher episodic memory abilities would have greater intention of changing their high-risk behaviour in the near future. More particularly, our data showed an association with a specific episodic memory score: the ' $R$ answers'. This measure refers to conscious recollection involving retrieval of a personal event and features about its encoding context (Gardiner et al., 2002). We can assume that higher episodic memory functioning promotes patients' engagement in the 'consciousness-raising' process. This hypothesis is supported by the findings of Blume et al. (2005) suggesting that intact verbal memory performance favours awareness of difficulties arising from alcohol consumption. 'Consciousness-raising' refers to an increase in the level of awareness about the origins, consequences and treatment possibilities of inappropriate behaviour such as excessive 21 alcohol consumption. It is achieved when patients are able to access information about alcohol-dependence to supplement their own knowledge about their disease. balance' (Janis and Mann, 1977) evaluating the perceived advantages and disadvantages of consuming alcohol or quitting drinking. This 'decisional balance' enables them move on to 
1 the next stages of change. Alcohol-dependent patients are ambivalent and oscillate between

2 their impulsive 'limbic' behaviour and more controlled behaviour subtended by frontal lobe

3 activity (Crews and Boettiger, 2009). Our study revealed that patients with lower motivation

4 to change also had lower executive functioning including deficits of inhibition, mental 5 flexibility, problem-solving and rule abstraction. These findings suggest that efficient 6 executive functioning is necessary to go through "decisional balance".

Finally, our statistical analysis demonstrated a relationship between higher decisionmaking abilities and higher action stage scores. This observation could imply that patients early in abstinence who have problems making decisions (Noel et al., 2007) experience greater difficulty resolving decisional balance and moving towards a strong desire for change.

They must hone their decision-making faculties in order to detect risks related to alcohol in

12 the everyday life situations. They also have to glean information about causes and outcomes from past experiences and project themselves into the future. However, some patients who are addicted to alcohol or other substances and who have decision-making disorders may have difficulty anticipating the future. They prefer choices that bring an immediate benefit, even if they are harmful in the long term (loss of work and family or social deterioration) (Bechara et al., 2001; Bechara et al., 2002; Goudriaan et al., 2005; Noel et al., 2007).

To sum up, cognitive performance may predict the level of motivation of alcoholdependent patients at treatment entry and must be taken into account in clinical decisions.

\section{Clinical implications and limitations}

High cognitive functioning including efficient episodic memory, executive functions and decision-making abilities seems essential to enhance readiness to change drinking behaviour. The neuropsychological screening of possible cognitive impairments may prove to be extremely useful at alcohol treatment entry and have to be taken into account to make 
1 relevant clinical decisions and choose the most appropriate treatment according to the

2 patients' level of motivation. As a consequence of their cognitive deficits, some alcohol-

3 dependent patients may not be able to undergo the standard treatment in an addictology

4 department because of their low motivation. In alcohol-dependence, several studies have

5 shown that cognitive disorders are at least partly reversible with abstinence (Rourke and

6 Grant, 1999; Pitel et al., 2009). Therefore, once patients have physically completed

7 detoxification, it may be a good idea to favour the neuropsychological recovery of those who

8 display cognitive deficits by extending the period they spend without alcohol (e.g., in-patient

9 follow-up rehabilitation) before being admitted to the addictology department. It would also

10 be interesting to promote spontaneous neuropsychological recovery by using rehabilitation

11 techniques used with brain-injured patients.

12 One of the limitations of this study is that it was carried out with a very particular sample of alcohol-dependent patients, as our aim was to explore readiness to change at a specific point in the clinical course of alcohol dependence (i.e., at alcohol treatment entry, early in abstinence). Although we are sure that cognitive performance was not influenced by acute alcohol consumption, our findings cannot, nevertheless, be extended to the general clinical population of alcohol-dependent patients. Therefore, other studies are needed to provide information about the link between motivation and cognitive skills in patients with alcohol abuse or dependence who are not receiving clinical treatment and who continue to drink alcohol. Another limitation is that as the gender distribution of our alcohol-dependent 21 group reflected the gender distribution that prevails in most alcohol treatment departments in 22 France, our results are mainly representative of alcohol-dependent men. Moreover, although the lack of motivation could partly be explained by cognitive impairment, the move towards higher readiness to change relies on many processes of change which, in turn, rely not only on higher-level cognitive functions but also on emotional and social skills including theory of 
1 mind, empathy and self. Further studies are therefore needed to assess the possible

2 impairment of social cognition in alcohol-dependence and the latter's links - if any - with the 3 multidimensional phenomenon of motivation.

4 


\section{Acknowledgments}

2 The authors would like to thank Julia Rivier and Nezha Bissara for their help in 3 collecting the data.

4 


\section{Reference List}

Abbott MW, Gregson RA (1981) Cognitive dysfunction in the prediction of relapse in alcoholics. J Stud Alcohol 42: 230-43.

Allsop S, Saunders B, Phillips M (2000) The process of relapse in severely dependent male problem drinkers. Addiction 95: 95-106.

American Psychiatric Association (1994) Diagnostic and Statistical Manual of Mental Disorders. American Psychiatric Association, Washington.

Beatty WW, Katzung VM, Moreland VJ, Nixon SJ (1995) Neuropsychological performance of recently abstinent alcoholics and cocaine abusers. Drug Alcohol Depend 37: 247253.

Bechara A, Damasio AR, Damasio H, Anderson SW (1994) Insensitivity to future consequences following damage to human prefrontal cortex. Cognition 50: 7-15.

Bechara A, Dolan S, Denburg N, Hindes A, Anderson SW, Nathan PE (2001) Decisionmaking deficits, linked to a dysfunctional ventromedial prefrontal cortex, revealed in alcohol and stimulant abusers. Neuropsychologia 39: 376-389.

Bechara A, Dolan S, Hindes A (2002) Decision-making and addiction (part II): myopia for the future or hypersensitivity to reward? Neuropsychologia 40: 1690-1705.

Beck AT, Ward CH, Mendelson M, Mock J, Erbaugh J (1961) An inventory for measuring depression. Arch Gen Psychiatry 4: 561-571. 
1 Blume AW, Davis JM, Schmaling KB (1999) Neurocognitive dysfunction in duallydiagnosed patients: a potential roadblock to motivating behavior change. J Psychoactive Drugs 31: 111-115.

Blume AW, Marlatt GA (2009) The role of executive cognitive functions in changing substance use: what we know and what we need to know. Ann Behav Med 37: 117125.

Blume AW, Marlatt GA, Schmaling KB (2000) Executive cognitive function and heavy drinking behavior among college students. Psychol Addict Behav 14: 299-302.

Blume AW, Schmaling KB, Marlatt GA (2005) Memory, executive cognitive function, and readiness to change drinking behavior. Addict Behav 30: 301-314.

Burgess PW, Shallice T (1996) Response suppression, initiation and strategy use following frontal lobe lesions. Neuropsychologia 34: 263-272.

Cardebat D, Doyon B, Puel M, Goulet P, Joanette Y (1990) Formal and semantic lexical evocation in normal subjects. Performance and dynamics of production as a function of sex, age and educational level. Acta Neurol Belg 90: 207-217.

Carney MM, Kivlahan DR (1995) Motivational subtypes among veterans seeking substance abuse treatment: profiles based on stages of change. Psychol Addict Behav 9: 135142.

Crews FT, Boettiger CA (2009) Impulsivity, frontal lobes and risk for addiction. Pharmacol Biochem Behav 93: 237-247.

DiClemente CC (2007) Mechanisms, determinants and processes of change in the modification of drinking behavior. Alcohol Clin Exp Res 31: 13s-20s. 
1 DiClemente CC, Bellino LE, Neavins TM (1999) Motivation for change and alcoholism treatment. Alcohol Res Health 23: 86-92.

3 DiClemente CC, Doyle SR, Donovan D (2009) Predicting treatment seekers' readiness to

4

5 change their drinking behaviour in the COMBINE study. Alcohol Clin Exp Res 33: 879-892.

DiClemente CC, Hughes SO (1990) Stages of change profiles in outpatient alcoholism treatment. J subst Abuse 2: 217-235.

Donovan DM, Kivlahan DR, Walker RD (1984) Clinical limitations of neuropsychological testing in predicting treatment outcome among alcoholics. Alcohol Clin Exp Res 8: $470-5$.

Edens JF, Willoughby FW (2000) Motivational patterns of alcohol dependent patients: A replication. Psychol Addict Behav 14: 397-400.

Fama R, Pfefferbaum A, Sullivan EV (2004) Perceptual learning in detoxified alcoholic men: contributions from explicit memory, executive function, and age. Alcohol Clin Exp Res 28: 1657-1665.

Folstein MF, Folstein SE, McHugh PR (1975) "Mini-mental state". A practical method for grading the cognitive state of patients for the clinician. J Psychiatr Res 12: 189-198.

Gardiner JM, Ramponi C, Richardson-Klavehn A (2002) Recognition memory and decision processes: a meta-analysis of remember, know, and guess responses. Memory 10: 8398.

Glenn SW, Parsons OA (1991) Prediction of resumption of drinking in posttreatment alcoholics. Int J Addict 26: 237-54. 
1 Godefroy O (2001) Groupe de Réflexion sur l'Evaluation des Fonctions Exécutives (GREFEX). L'évaluation des fonctions exécutives en pratique clinique. Rev Neuropsychol 11: 383-434.

Goldstein RZ, Leskovjan AC, Hoff AL, Hitzemann R, Bashan F, Khalsa SS, Wang GJ, (1) Fowler JS, Volkow ND (2004) Severity of neuropsychological impairment in cocaine and alcohol addiction: association with metabolism in the prefrontal cortex. Neuropsychologia 42: 1447-1458.

Goudriaan AE, Oosterlaan J, de Beurs E, van den Brink W (2005) Decision making in pathological gambling: a comparison between pathological gamblers, alcohol dependents, persons with Tourette syndrome, and normal controls. Brain Res Cogn Brain Res 23: 137-151.

Gregson RA, Taylor GM (1977) Prediction of relapse in men alcoholics. J Stud Alcohol 38: 1749-60.

Grober E, Buschke H (1987) Genuine memory deficits in dementia. Dev Neuropsychol 3: 1336.

Grober E, Buschke H, Crystal H, Bang S, Dresner R (1988) Screening for dementia by memory testing. Neurology 38: 900-903.

Hettema J, Steele J, Miller WR (2005) Motivational interviewing. Annu Rev Clin Psychol 1: 91-111.

Janis IL, Mann L (1977) Emergency decision making: a theoretical analysis of responses to disaster warnings. J Human Stress 3: 35-45. 
1 Jin H, Rourke SB, Patterson TL, Taylor MJ, Grant I (1998) Predictors of relapse in long-term abstinent alcoholics. J Stud Alcohol 59: 640-6.

3 Le Berre AP, Pinon K, Vabret F, Pitel AL, Allain P, Eustache F, Beaunieux H (2010) Study of metamemory in patients with chronic alcoholism using a feeling-of-knowing episodic memory task. Alcohol Clin Exp Res 34: 1888-1898.

Lezak MD, Howieson DB, Loring DW, Hannay HJ, Fischer JS (2004) Neuropsychological Assessment. 4th ed. Oxford University Press, New York.

Macciocchi SN, Ranseen JD, Schmitt FA (1989) The relationship between neuropsychological impairment in alcoholics and treatment outcome at one year. Arch Clin Neuropsychol 4: 365-70.

Meulemans T, Steyaert M, Vincent E (2001, May) Evaluation des déficits d'inhibition chez les patients traumatisés crâniens à l'aide du test de Hayling. Poster session presented at the Journées de Printemps of the Société de Neuropsychologie de Langue Française, Lyons, France.

Miller L (1991) Predicting relapse and recovery in alcoholism and addiction: neuropsychology, personality, and cognitive style. J Subst Abuse Treat 8: 277-91.

Miller WR, Rose GS (2009) Toward a theory of motivational interviewing. Am Psychol 64: $527-537$.

Moriyama Y, Mimura M, Kato M, Yoshino A, Hara T, Kashima H, Kato A, Watanabe A (2002) Executive dysfunction and clinical outcome in chronic alcoholics. Alcohol Clin Exp Res 26: 1239-44. 
1 Moselhy HF, Georgiou G, Kahn A (2001) Frontal lobe changes in alcoholism: a review of the literature. Alcohol Alcohol 36: 357-368.

Nelson HE (1976) A modified card sorting test sensitive to frontal lobe defects. Cortex 12: 313-324.

Nelson TO (1984) A comparison of current measures of the accuracy of feeling-of-knowing predictions. Psychol Bull 95: 109-133.

Noel X, Bechara A, Dan B, Hanak C, Verbanck P (2007) Response inhibition deficit is involved in poor decision making under risk in nonamnesic individuals with alcoholism. Neuropsychology 21: 778-786.

Noel X, Sferrazza R, Van der Linden M, Paternot J, Verhas M, Hanak C, Pelc I, Verbanck P (2002) Contribution of frontal cerebral blood flow measured by (99m)Tc-Bicisate spect and executive function deficits to predicting treatment outcome in alcoholdependent patients. Alcohol Alcohol 37: 347-54.

Noel X, Van der Linden M, Schmidt N, Sferrazza R, Hanak C, Le Bon O, De Mol J, Kornreich C, Pelc I, Verbanck P (2001) Supervisory attentional system in nonamnesic alcoholic men. Arch Gen Psychiatry 58: 1152-1158.

Parsons OA (1994) Neuropsychological measures and event-related potentials in alcoholics: interrelationships, long-term reliabilities, and prediction of resumption of drinking. $\mathbf{J}$ Clin Psychol 50: 37-46.

Parsons OA, Schaeffer KW, Glenn SW (1990) Does neuropsychological test performance predict resumption of drinking in posttreatment alcoholics? Addict Behav 15: 297307. 
1 Penberthy JK, Ait-Daoud N, Breton M, Kovatchev B, DiClemente CC; Johnson BA (2007) Evaluating readiness and treatment seeking effects in a pharmacotherapy trial for alcohol dependence. Alcohol Clin Exp Res 31: 1538-1544.

Pinon K, Allain P, Kefi MZ, Dubas F, Le Gall D (2005) Monitoring processes and metamemory experience in patients with dysexecutive syndrome. Brain Cogn 57: 185188.

Pitel AL, Beaunieux H, Witkowski T, Vabret F, Guillery-Girard B, Quinette P, Desgranges B, Eustache F (2007) Genuine episodic memory deficits and executive dysfunctions in alcoholic subjects early in abstinence. Alcohol Clin Exp Res 31: 1169-1178.

Pitel AL, Rivier J, Beaunieux H, Vabret F, Desgranges B, Eustache F (2009) Changes in the episodic memory and executive functions of abstinent and relapsed alcoholics over a 6-month period. Alcohol Clin Exp Res 33: 490-498.

Project MATCH Research Group (1997) Project MATCH secondary a priori hypotheses. Addiction 92: 1671-1698.

Project MATCH Research Group (1998) Matching alcoholism treatments to client heterogeneity: project MATCH three-year drinking outcomes. Alcohol Clin Exp Res 22:1300-1311.

Prochaska JO, DiClemente CC (1983) Stages and processes of self-change of smoking: toward an integrative model of change. J Consult Clin Psychol 51: 390-395.

Reitan RM (1958) The validity of the Trail Making Test as an indicator of organic brain damage. Percept Mot Skills 8: 271-276. 
1 Rollnick S, Heather N, Gold R, Hall W (1992) Development of a short 'readiness to change' questionnaire for use in brief, opportunistic interventions among excessive drinkers. Br J Addict 87: 743-754.

4 Rourke SB, Grant I (1999) The interactive effects of age and length of abstinence on the recovery of neuropsychological functioning in chronic male alcoholics: a 2-year follow-up study. J Int Neuropsychol Soc 5: 234-246.

7 Severtson SG, von Thomsen S, Hedden SL, Latimer W (2010) The association between 8 executive functioning and motivation to enter treatment among regular users of heroin and/or cocaine in Baltimore, MD. Addict Behav 35: 717-720.

Spielberger CD, Gorsuch RL, Lushene R, Vagg PR, Jacobs GA (1983) Manual for the StateTrait Anxiety Inventory (form Y). Consulting Psychologists Press, Palo Alto, CA.

12 Stroop J (1935) Studies of interference in serial verbal reactions. J Exp Psychol 18: 643-662.

13 Sullivan EV, Rosenbloom MJ, Pfefferbaum A (2000) Pattern of motor and cognitive deficits in detoxified alcoholic men. Alcohol Clin Exp Res 24: 611-621. selective and divided attention tasks. Drug Alcohol Depend 75 277-286. 
2

3 Fig. 1. Scatterplot illustrating the relationship between (A) the Precontemplation subscale

4 score and the Recollection score (\%); (B) the Contemplation subscale score and the inhibition

5 score (Stroop test Colour-Word time); and (C) the Action subscale score and the decision-

6 making measure in the alcohol-dependent group.

7

8

9 
$\underline{\text { Table Legends }}$

2 Table 1. Participants' main demographic and clinical features

3

4 Table 2. Patients' readiness to change

5

6 Table 3. Assessment of episodic memory, metamemory, executive functions and decision-

7 making in controls and alcohol-dependent patients

8 
1 Table 1. Participants' main demographic and clinical features

\begin{tabular}{|c|c|c|c|c|}
\hline & $\begin{array}{l}\text { Controls } \\
(N=37)\end{array}$ & $\begin{array}{l}\text { Alcohol-dependent } \\
\text { patients } \\
(N=31)\end{array}$ & $t$ & $p$ value \\
\hline $\begin{array}{l}\text { Age } \\
\text { Range }\end{array}$ & $\begin{array}{l}45.49(6.07) \\
31-60\end{array}$ & $\begin{array}{l}43.87(6.97) \\
31-56\end{array}$ & -1.02 & 0.31 \\
\hline $\begin{array}{l}\text { Years of education } \\
\text { Range }\end{array}$ & $\begin{array}{l}12.11(3.56) \\
5-20\end{array}$ & $\begin{array}{l}10.77(2.14) \\
6-15\end{array}$ & -1.82 & 0.07 \\
\hline MMSE & $29.46(0.77)$ & $27.35(1.68)$ & -6.81 & $0.001^{* *}$ \\
\hline Beck Depression Inventory & $1.54(2.01)$ & $7.68(3.49)$ & 1 & $0.001^{*}$ \\
\hline $\begin{array}{l}\text { State-Trait Anxiety Inventory } \\
\text { "State anxiety" (STAI Y-A) }\end{array}$ & $29.22(9.12)$ & $33.84(9.89)$ & I & $0.05^{*}$ \\
\hline $\begin{array}{l}\text { State-Trait Anxiety Inventory } \\
\text { "Trait anxiety" (STAI Y-B) }\end{array}$ & $33.22(7.20)$ & $50.77(14.41)$ & I & $0.001^{*}$ \\
\hline Days of sobriety before inclusion & 1 & $12.64(7.16)$ & I & 1 \\
\hline Range & 1 & $7-40$ & I & 1 \\
\hline Years of alcohol-dependence & 1 & $8.26(8.26)$ & 1 & 1 \\
\hline Range & 1 & $0.5-33$ & I & 1 \\
\hline $\begin{array}{l}\text { Quantity per day (in units of } \\
\text { alcohol) }\end{array}$ & I & $21.95(11.70)$ & / & 1 \\
\hline Range & 1 & $3.5-53.57$ & 1 & 1 \\
\hline
\end{tabular}

2 Data are shown as means (standard deviation).

$3{ }^{* *}$ Significant difference between alcohol-dependent patients and controls $(p<0.05)$ for unpaired parametric Student's paired $t$-test

* Significant difference between alcohol-dependent patients and controls $(p<0.05)$ for nonparametric Kolmogorov-Smirnov test 
1 Table 2. Patients' readiness to change

\begin{tabular}{ll}
\hline Precontemplation subscale score & $-2.13(3.40)$ \\
Range & $-8-5$ \\
\hline Contemplation subscale score & $1.03(5.28)$ \\
Range & $-8-8$ \\
\hline Action subscale score & $5.35(2.83)$ \\
Range & $-4-8$ \\
\hline
\end{tabular}

2 Data are shown as means (standard deviation).

3 
1 Table 3. Assessment of episodic memory, metamemory, executive functions and decision-

2 making in controls and alcohol-dependent patients

\begin{tabular}{|c|c|c|c|c|c|}
\hline & Tasks & Controls & $\begin{array}{l}\text { Alcohol- } \\
\text { dependent } \\
\text { patients }\end{array}$ & $t$ & $p$ value \\
\hline \multicolumn{6}{|l|}{ Verbal Episodic Memory } \\
\hline Learning & $\begin{array}{l}\text { sum of the three free } \\
\text { recall scores, FCSRT }\end{array}$ & $21.07(4.98)$ & $30.03(5.01)$ & -4.29 & $0.001^{*}$ \\
\hline Encoding & $\begin{array}{l}\text { recognition in the } \\
\text { 'spontaneous' condition, } \\
\text { Spondee test }\end{array}$ & $0.86(0.11)$ & $0.77(0.13)$ & -3.18 & $0.005^{*}$ \\
\hline Retrieval & $\begin{array}{l}\text { free recall in the 'deep' } \\
\text { condition, Spondee test }\end{array}$ & $0.60(0.16)$ & $0.46(0.18)$ & -3.08 & $0.005^{*}$ \\
\hline Recollection & $\mathrm{R}$ answers, Spondee test & $0.77(0.17)$ & $0.66(0.25)$ & -2.04 & $0.05^{*}$ \\
\hline \multicolumn{6}{|l|}{ Metamemory } \\
\hline & FOK gamma correlation & $0.25(0.50)$ & $-0.01(0.54)$ & 2.09 & $0.05^{*}$ \\
\hline \multicolumn{6}{|l|}{ Executive Functions } \\
\hline Spontaneous flexibility & Verbal fluency & $61.57(12.28)$ & $56.06(14.95)$ & -1.67 & 0.10 \\
\hline \multirow{4}{*}{ Inhibition } & $\begin{array}{l}\text { Stroop test Colour-Word } \\
\text { time }\end{array}$ & $98.27(22.60)$ & $115.13(29.51)$ & 2.66 & $0.01^{*}$ \\
\hline & $\begin{array}{l}\text { Stroop test Colour-Word } \\
\text { errors }\end{array}$ & $0.78(1.16)$ & $2.68(3.65)$ & 2.98 & $0.005^{*}$ \\
\hline & Hayling Part B time & $64.76(34.38)$ & $76.39(40.17)$ & 1.29 & 0.20 \\
\hline & Hayling Part B penalties & $6.67(16.09)$ & $7.77(4.14)$ & 0.40 & 0.71 \\
\hline \multirow{2}{*}{ Reactive flexibility } & TMT B time & $62.05(20.50)$ & $77.10(34.51)$ & 2.23 & $0.05^{*}$ \\
\hline & TMT B errors & $0.24(0.49)$ & $3.77(18.06)$ & 1.19 & 0.24 \\
\hline \multirow{3}{*}{$\begin{array}{l}\text { Set-shifting } \\
\text { Problem-solving } \\
\text { Rule abstraction }\end{array}$} & MCST time & $268.24(98.22)$ & $\begin{array}{l}357.81 \\
(165.88)\end{array}$ & 2.76 & $0.01 *$ \\
\hline & MCST categories & $5.73(0.61)$ & $4.93(1.55)$ & -2.87 & $0.005^{*}$ \\
\hline & MCST errors & $5.51(2.40)$ & $11.06(5.78)$ & 2.94 & $0.005^{*}$ \\
\hline \multicolumn{6}{|l|}{ Decision-Making } \\
\hline 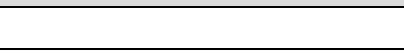 & lowa Gambling Task & $18.06(26.33)$ & $6.45(17.81)$ & 2.15 & $0.05^{*}$ \\
\hline
\end{tabular}


1 Table 4. Correlations between age, years of education, MMSE, psychiatric data (BDI and

2 STAI), drinking variables and 'readiness to change' subscales

\begin{tabular}{lllll} 
& & $\begin{array}{l}\text { precontemplation } \\
\text { subscale }\end{array}$ & $\begin{array}{l}\text { contemplation } \\
\text { subscale }\end{array}$ & $\begin{array}{l}\text { action } \\
\text { subscale }\end{array}$ \\
\hline age & 0.27 & 0.07 & 0.06 \\
\hline Years of education & -0.03 & -0.16 & 0.01 \\
\hline MMSE & -0.06 & -0.24 & 0.13 \\
\hline Beck Depression Inventory & 0.27 & 0.02 & -0.17 \\
\hline $\begin{array}{l}\text { State-Trait Anxiety Inventory “State } \\
\text { anxiety" (STAI Y-A) }\end{array}$ & 0.17 & 0.03 & 0.04 \\
\hline $\begin{array}{l}\text { State-Trait Anxiety Inventory } \\
\text { "Trait anxiety" (STAI Y-B) }\end{array}$ & 0.02 & 0.13 & -0.24 \\
\hline $\begin{array}{llll}\text { Days of sobriety before inclusion } \\
\text { Years of alcohol-dependence }\end{array}$ & 0.11 & -0.15 & 0.09 \\
\hline & 0.02 & 0.03 & -0.24 \\
\hline & Quantity per day (in units of alcohol) & -0.14 & -0.09 & $-0.40^{*}$ \\
\hline * p<0.05 & & &
\end{tabular}


1 Table 5. Cognitive predictors of 'readiness to change' subscale in alcohol-dependent patients

\begin{tabular}{|c|c|c|c|c|}
\hline $\begin{array}{l}\text { Dependent } \\
\text { variable }\end{array}$ & Independent variable & $\beta$ coefficient & Standard error of $\beta$ & $p$ value \\
\hline $\begin{array}{l}\text { precontemplation } \\
\text { subscale }\end{array}$ & $R$ answers & -0.44 & 0.17 & 0.013 \\
\hline $\begin{array}{l}\text { contemplation } \\
\text { subscale }\end{array}$ & $\begin{array}{l}\text { Stroop test Colour-Word time } \\
\text { MCST errors }\end{array}$ & $\begin{array}{l}0.42 \\
0.39\end{array}$ & $\begin{array}{l}0.15 \\
0.15\end{array}$ & $\begin{array}{l}0.009 \\
0.015\end{array}$ \\
\hline $\begin{array}{l}\text { action } \\
\text { subscale }\end{array}$ & $\begin{array}{l}\text { decision-making measure (lowa } \\
\text { Gambling Task) }\end{array}$ & 0.43 & 0.17 & 0.015 \\
\hline
\end{tabular}

2 